\title{
Güneydoğu Anadolu Bölgesi çeltik alanlarında yeni bir zararlı: Tipula orientalis Laskschewitz (Diptera: Tipulidae)
}

\author{
A new pest in rice growing fields in Southeastern Anatolia: Tipula orientalis \\ Laskschewitz (Diptera: Tipulidae)
}

Mehmet DUMAN $^{1 *}$

Çetin MUTLU ${ }^{1}$

Musa BÜYÜK²

\begin{abstract}
Summary
This study was carried out in rice growing fields of Karacadağ rice variety, which has specific smell and aroma in Southeast Anatolia Region and preferred by residents of that area, within borders of Şanlıurfa province (Siverek Üzümlük) and Diyarbakır province (Ergani Demirli, Çınar Kuyuluhöyük, Hazro Düzevler) during the years 2010 and 2011. The study was conducted in order to determine distribution and population change of Tipula orientalis Laskschewitz (Diptera: Tipulidae) have been conducted in Ergani and Demirli village. Sampling of $T$. orientalis have been performed by using hand-picking, D-vac and sweeping net.

The results indicated that the first adults of the pest have been seen at the end of May and they have been seen during period of May to October in both years. However, the pest reached its highest level at June-July and created two peak points. The adults of $T$. orientalis continued until mid of the October which was harvesting time for rice. The highest adults (55 adults) were caught by way of D-vac on 29 June 2010 in Siverek-Üzümlük, while 37 adults/ sweeping net were recorded in Ergani- Demirli on 9 July 2011.

According to the results of this study it was determined that the larvae of $T$. orientalis were active and cause damage from the end of May, which was planting time for rice, during months of June and July, however, the adults of this fly were active until harvesting time. In addition, the infestation ratio, males, females and larvae of the pest have been determined in the research area.
\end{abstract}

Keywords: Karacadağ rice, population development, Tipula orientalis

\section{Özet}

Bu çalışma Güneydoğu Anadolu Bölgesi'nde kendine has kokusu ve aroması bulunan ve yöre insanı tarafından tercih edilen Karacadağ çeltik alanlarında 2010-2011 yıllarında Şanlıurfa (Siverek-Üzümlük), Diyarbakır (Ergani-Demirli, Çınar-Kuyuluhöyük ve Hazro-Düzevler) köylerinde bostan sineği Tipula orientalis Laskschewitz (Diptera: Tipulidae)'in bulaşıklık durumunu ve popülasyon değişimini belirlemek amacıyla yürütülmüştür. Örneklemelerde atrap, D-vac ve elle toplama yöntemleri kullanılmıştır.

Çalışmada elde edilen sonuçlara göre; $T$. orientalis'in ilk ergin çıkışı çeltik ekiminin yapıldığı mayıs ayının sonunda başlamış ve çalışmanın her iki yılında da mayıs-eylül ayları boyunca görülmüş ancak zararlı HaziranTemmuz aylarında en yüksek seviyeye ulaşarak iki tepe noktası oluşturmuştur. Bostan sineğine ait ergin uçuşları hasadın yapılacağı tarih olan ekim ayının ortalarına kadar sürmüştür. Atrap ve D-vac yardımı ile 2010 yılında yakalanan ergin sayısı en fazla 55 ergin/D-vac Siverek Üzümlük köyünde (29.VI.2010) bulunurken, 2011 yılında ise 37 ergin/atrap (09.VII.2011) ile Ergani Demirli köyünde gerçekleşmiştir. Bu çalışma ile T.orientalis'in çeltiğin ekildiği Mayıs ayının sonundan Haziran ve Temmuz aylarına kadar larvalarıın aktif olduğu ve zarar verdiği ancak erginlerinin ise hasada kadar doğada aktif olarak bulunduğu tespit edilmiştir. Ayrıca çalışmanın yürütüldüğü her iki alanın da zararlı ile bulaşıklık olduğu tespit edilmiş, zararlının erkek, dişi ve larvalarının tanımı yapıımışıı.

Anahtar sözcükler: Karacadağ çeltiği, popülasyon gelişimi, Tipula orientalis

\footnotetext{
${ }^{1}$ Zirai Mücadele Araştırma İstasyon Müdürlüğü, Silvan yolu, 7. km. PK. 115 -21110, Diyarbakır

${ }^{2}$ Dicle Üniversitesi, Ziraat Meslek Yüksekokulu, Diyarbakır.

* Sorumlu yazar (Corresponding author) email: mduman_53@hotmail.com

Alınış (Received): 13.03.2014

Kabul ediliş (Accepted): 21.07.2014
} 


\section{Giriş}

Çeltik eski bir kültür bitkisidir. Gen merkezinin Güneydoğu Asya'da Hindistan ve Çin olduğu tahmin edilmektedir. Su içinde çimlenebilen ve kökleri suda erimiş oksijenden yararlanabilen tek tahıl cinsi olan çeltik, besin kaynağı olarak tahıllar içinde buğdaydan sonra gelen en önemli üründür. Çeltiğin; tuzlu ve alkali arazilerde yetişmesi, bu arazilerin ıslahında etkili olması ve ekonomik açıdan yüksek verim sağlaması nedeniyle Türkiye tarımında önemli rol oynadığı belirtilmektedir. Çeltik aynı zamanda dünyadaki insanların yarıdan fazlasının ana besin kaynağıdır. Çeltik üretimi bakımından dünyada önde gelen ülkeler; Çin, Hindistan, Endonezya, Bangladeş ve Vietnam'dır. Dünya çeltik verimi ise ortalama 410 kg/da'dır (Anonymous, 2013). Türkiye'de kişi başına pirinç tüketimi 7-9 kg arasında değişmektedir. Pirinç tüketiminin nüfus artışına paralel olarak arttığı düşünüldüğünde gelecek yıllarda pirinç talebinin daha da artacağı tahmin edilmektedir. Türkiye uzun yıllardan beri iç talebi karşılamak için belirli miktarlarda her yıl pirinç ithal etmektedir. Nüfusumuzun yıllık toplam pirinç talebi yaklaşık olarak 560 bin tondur ve bu miktarın 350-450 bin tonu yurtiçi üretimle, kalan kısmı ithalatla karşılanmaktadır (Anonymous, 2013).

Güneydoğu Anadolu Bölgesi'nde 2010 yılında çeltik üretiminin \% 98'i Şanlıurfa ve Diyarbakır illerinde 59.149 da alanda gerçekleşmiş (Anonymous, 2010) ve Diyarbakır'daki alanların tamamında yerel Karacadağ çeltik çeşidi kullanılmıştır. Karacadağ çeltik çeşidi Diyarbakır, Şanlıurfa Siverek İlçesi ve Mardin'in Derik İlçesi'nde çoğunlukla da Karacadağ Bölgesi'nde yetiştirilmekte ve kır çeltikçiliği şeklindedir. Toprak işlemesi yapılmaksızın, sulama tavaları oluşturulmadan, genellikle tarla tarımına elverişli olmayan taşlık ve eğimli alanlarda 2-7 yılda bir aynı tarlaya çeltik ekimi yapılmaktadır. Çiftçiler eldeki sudan maksimum faydalanmak için suyun durumuna göre ekim alanını arttırmakta ya da azaltmaktadır. Yağışın yetersiz olduğu yıllarda göletler dolmadığından üretim alanlarında düşüş meydana gelmektedir. Genellikle ekim öncesi toprak işleme, yabancı ot ilaçlaması, tohum ilaçlaması yapılmamaktadır.

Türkiye'de genelde çeltik, devamlı sulama ile tarla su altında tutularak yetiştirilir. Ancak bölgede su tavaları oluşturulmadan, salma sulama metodu ile tarlalar 24-72 saat arayla sulanmakta olup hasattan 510 gün önce su kesilmektedir. Çeltik alanlarının sulaması yapay sulama göletlerden, sondaj kuyularından ve doğal kaynak sularından faydalanılarak yapılmaktadır. Bostan sineği, Tipula orientalis Laskschewitz (Diptera: Tipulidae) larvası, bu yetiştirme şeklinden dolayı çeltiğin ilk 5-6 haftalık yetiştirme periyodunda gelişmekte ve zarar yapmaktadır. Bu alanlarda ana zararlı konumunda olmayıp hayatını sürdürmektedir.

Sıcak ilkbahar ve yaz aylarında genellikle akarsu kenarlarındaki nemli ve gölgeli yerlerde bulunan tipulidler iri vücutları, uzun bacakları ve hantal uçuşları ile kolayca tanınabilirler. Ergin evrede pek azında beslenme vardır. Bu da nektar veya serbest bitki öz sularını emme şeklindedir. Yumurtlama çiftleşmeden hemen sonra meydana gelir ve yumurta genelde nemli toprağa veya çamura bırakılır. Toprak içinde bulunan yumurtaların yaşama şansı su içindeki larvalardan daha fazladır. Uzun ve silindirik yapılı olan larvalar dayanıklı derili ve 12 segmentlidir. Baş kapsülü büyüktür ve çoğunlukla protoraksın içine girer (hemicephal). Vücutlarının son segmentinin ventralinde kirpikli boru ve solunum borusu bulunur. Yeterli miktarda nemin ve besinin ortamda bulunuşu larval safha için oldukça önemlidir. Akarsu, göl ve bataklık gibi nemli yerlerde çürümekte olan bitkilerin kök, gövde ve yaprakları, rutubetli tarla toprakları, sığır gübresi, ağaç kovukları, ağaçların yosunlu ya da çürük kısımları, nemli orman altı toprak tabakası larvaların gelişimi için uygun habitatlardır. Larvaların büyük bir kısmı saprofit, bir kısmı fitofag olup yaprak, kök ve odun yerler. Tarımsal ürün zararlısı olarak bilinen larvaları özellikle tarımsal ürünlere, ormanlardaki ağaçların kök ve genç sürgünlerine zarar verirler. Bitkilerin ya da fidanların sürgünlerini toprak üzerinden ya da altından keserek koparırılar (Şekil 2 b).

Türkiye'de ve dünyada tarımı yapılan birçok kültür bitkisinde modern tarımsal tekniklerinin uygulanmasının yanı sıra doğru, uygulanabilir ve bilinçli bir zirai mücadele uygulanması vazgeçilmez bir gerçektir. Bu da o zararının doğru tanınması, zarar yaptığı dönemin ve zarar şeklinin iyi bilinmesi ile 
mümkün olmaktadır. Diyarbakır ve Şanlıurfa illeri çeltik alanlarında $T$. orientalis'in zarar durumu, ergin ve larva tanımı ve popülasyon gelişimi ile ilgili herhangi bir çalışmanın olmaması nedeniyle bu çalışma yapılmıştır. Çalışmada, Diyarbakır ve Şanlıurfa'da Karacadağ çeltiği ekili alanlarda $T$. orientalis'in ekimden hasada kadar olan popülasyon gelişimi, larva ve ergin tanımları, bitkideki zarar durumu ve popülasyonunun en yüksek olduğu dönemlerin belirlenmesi amaçlanmıştır.

\section{Materyal ve Yöntem}

Çalışmanın ana materyalini Bostan sineği, Tipula orientalis Laskschewitz,(Diptera: Tipulidae) ile bulaşık çeltik tarlaları oluşturmuştur. Bu çalışma 2010-2011 yıllarında T. orientalis'in erginlerinin Karacadağ çeltiği ekili alanlardaki bulaşıklık oranı ve popülasyon gelişiminin belirlenmesi amacıyla Diyarbakır (Ergani-Demirli, Çınar-Kuyuluhöyük ve Hazro-Düzevler) ve Şanlıurfa (Siverek-Üzümlük) köylerinde, çeltik tarlalarında yürütülmüştür (Çizelge 1).

Çizelge 1. Diyarbakır ve Şanlıurfa illerinde Tipula orientalis'in ergin popülasyonunun izlendiği çeltik tarlaları

\begin{tabular}{|c|c|c|c|c|c|c|c|c|}
\hline \multirow[t]{2}{*}{ ì } & \multirow[t]{2}{*}{ İlçe } & \multirow[t]{2}{*}{ Köy } & \multicolumn{3}{|c|}{2010} & \multicolumn{3}{|c|}{2011} \\
\hline & & & Koordinat & Alan (da) & Rakım & Koordinat & Alan(da) & Rakım \\
\hline \multirow[t]{2}{*}{ Şanlıurfa } & \multirow[t]{2}{*}{ Siverek } & \multirow[t]{2}{*}{ Üzümlük } & $\mathrm{K}: 37^{\circ} 42^{\prime} 38.07^{\prime \prime K}$ & \multirow[t]{2}{*}{105} & \multirow[t]{2}{*}{$630 \mathrm{~m}}$. & $\mathrm{K}: 37^{\circ} 42^{\prime} 38.07^{\prime \prime K}$ & \multirow[t]{2}{*}{100} & \multirow[t]{2}{*}{$630 \mathrm{~m}}$. \\
\hline & & & D: 39¹4'46.33"D & & & D: 39¹4'46.33”D & & \\
\hline \multirow[t]{2}{*}{ Diyarbakır } & \multirow[t]{2}{*}{ Ergani } & \multirow[t]{2}{*}{ Demirli } & $\mathrm{K}: 37 \mathrm{~S} 563077 \mathrm{~K}$ & \multirow[t]{2}{*}{110} & \multirow[t]{2}{*}{$1057 \mathrm{~m}$} & $\mathrm{~K}: 37 \mathrm{~S} 563077 \mathrm{~K}$ & \multirow[t]{2}{*}{110} & \multirow[t]{2}{*}{$1057 \mathrm{~m}$} \\
\hline & & & D: 41895590D & & & D:41895590D & & \\
\hline \multirow[t]{2}{*}{ Diyarbakır } & \multirow[t]{2}{*}{ Hazro } & \multirow[t]{2}{*}{ Düzevler } & $\mathrm{K}: 38^{\circ} 10^{\prime} 07.23^{\prime \prime K}$ & \multirow[t]{2}{*}{140} & \multirow[t]{2}{*}{$821 \mathrm{~m}}$. & K: $38^{\circ} 10^{\prime} 07.23^{\prime \prime K}$ & \multirow[t]{2}{*}{140} & \multirow[t]{2}{*}{$821 \mathrm{~m}}$. \\
\hline & & & D: $40^{\circ} 44^{\prime} 29.87^{\prime \prime D}$ & & & D: $40^{\circ} 44^{\prime} 29.87^{\prime \prime D}$ & & \\
\hline \multirow[t]{2}{*}{ Diyarbakır } & \multirow[t]{2}{*}{ Çınar } & \multirow[t]{2}{*}{ Kuyuluhöyük } & $\mathrm{K}: 37^{\circ} 47^{\prime} 48.89^{\prime \prime K}$ & \multirow[t]{2}{*}{120} & \multirow[t]{2}{*}{$766 \mathrm{~m}}$. & $\mathrm{K}: 37^{\circ} 47^{\prime} 48.89^{\prime \prime K}$ & \multirow[t]{2}{*}{100} & \multirow[t]{2}{*}{$766 \mathrm{~m}}$. \\
\hline & & & D: $40^{\circ} 09^{\prime} 33.68 " D$ & & & D: $40^{\circ} 09^{\prime} 33.68 " \mathrm{D}$ & & \\
\hline
\end{tabular}

\section{Tipula orientalis'in zarar durumu ve bulaşıklık oranının belirlenmesi}

T. orientalis'in larvalarının bulaşıklık oranını belirlemek için, çalışmanın yürütüldüğü çeltik tarlalarında en fazla bulaşıklığın olduğu fide döneminde yani haziran ayında başlanmıştır. Bunun için sürvey yapılan iki tarlanın yirmi farklı yerinde bulunan çeltikte birbiri ardı sıra bulunan yirmi bitkide olmak üzere toplam 100 çeltik bitkisinde kök, gövde ve sürgünler dikkatli bir biçimde incelenerek larvanın kesik izleri aranmış ve üzerinde zararlının larvası bulunan bitkiler bulaşık olarak kabul edilmiştir. Bu şekilde her bir tarla için bulaşıklık oranı 100 sağlam bitkiye oranlanarak \% bulaşıklık oranı bulunmuştur. Bunun yanı sıra zararının larvaları 3 tekrarlı olarak $0,70 \times 0,70 \mathrm{~cm}$ ebadındaki üstü ve yan tarafları şeffaf tül ile kaplı olan kafesler içine alınıp ergin elde edilmeye çalışıımıştır.

\section{Tipula orientalis'in popülasyon gelişimi}

Ergin gelişimini belirlemek için atrap ve D-vac metodu kullanılmıştır. Örneklemelere her yılın mayıs ayında başlanmış, eylül ayında hasada kadar iki haftada bir olacak şekilde yürütülmüştür (Anonymous, 2009).

Atrap örneklemelerinde tarla kenarından içeriye 20 adım girildikten sonra tarla içinde zigzag çizilerek 20 atrap sallanmıştır. D-vac ile tarlanın 6 farklı noktasından birer dakika süreler ile çekimler yapılmıştır (Mutlu et al., 2008; Yılmaz \& Karsavuran, 2009). Toplanan materyal içinde kurutma kağıdı olan polietilen şeffaf torbalara konularak etiket bilgileri eklenmiş ve laboratuvara getirilmiştir. Laboratuvarda bitki artıklarından temizlenmiştir. D-vac aleti ile toplanan böcekleri içine alan bez torba her seferinde temizlenmiş, yenisi ile değiştirilmiş ve içerisinde materyal kalmamasına özen gösterilmiştir. 


\section{Bulgular ve Tartışma}

\section{Tipula orientalis'in tanımı}

Ergin : Erkek birey: abdomen topuzlu (Şekil 1 a), Dişi birey : Ovipozitor sivri (Şekil 1 b)

İnce ve uzun yapılı olan abdomen, 9 yada10 segmentten oluşmuştur. Abdomen sonu, dişilerde sivri olmakla birlikte erkekte daima genişlemiş ve özellikle önceki segmentten daha kalındır. Hypopygium olarak adlandırılan erkek terminali bir takım karakteristik yapılar taşır ki bu yapılar bilhassa türlerin ayrımında kullanılır. Hypopygium türler için karakteristik özellik gösteren bilhassa kitinleşmiş 9. segment ile çiftleşme organını (aeadegus) içerir. Ovipositör olarak adlandırılan dişi terminali yumurta bırakma ve çiftleşmeyi sağlayacak yapılar taşır. Ovipositör sivri ve kuvvetli kitinleşmiştir (Şekil 1).

Larva: Uzun ve silindirik yapılı olan larvalar dayanıklı derili ve 12 segmentlidir. Son abdomen segmentinde birbirinin yanında duran iki stigma bulunur. Baş kapsülü büyüktür ve çoğunlukla protoraksın içine girer (hemicephal). Sularda yaşayanlar öncelikle deri solunumu yaparlar ki bu solunum tipinde trake borucukları ile donatılmış vücut uzantıları önemli rol oynar. Vücutlarının son segmentinin ventralinde kirpikli boru ve solunum borusu bulunur. Lob şeklinde 6 tane stigma uzantısı vardır. Bu uzantılar, larva suyun dibine kaçınca veya çamura girince stigmaları kapatarak yabancı maddelerin içeri kaçmasını engeller. Larvalar, sucul, yarı sucul ya da bütünüyle karacıl olabilir. Akarsu, göl ve bataklık gibi nemli yerlerde çürümekte olan bitkilerin kök, gövde ve yaprakları(Şekil 2), rutubetli tarla toprakları, sığır gübresi, ağaç kovukları, ağaçların yosunlu ya da çürük kısımları, nemli orman altı toprak tabakası larvaların gelişimi için uygun habitatlardır. Larvaların büyük bir kısmı saprofittir (Şekil 2).

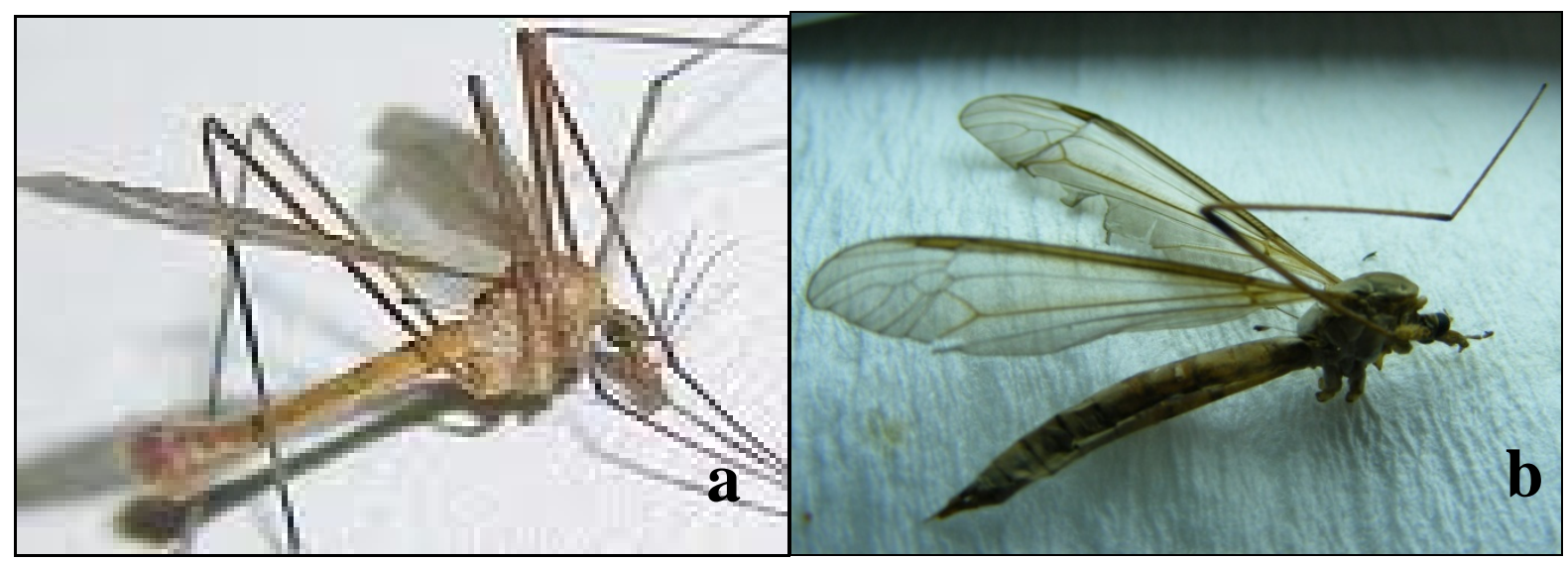

Şekil 1. Tipula orientalis erkek (a) ve dişi (b).

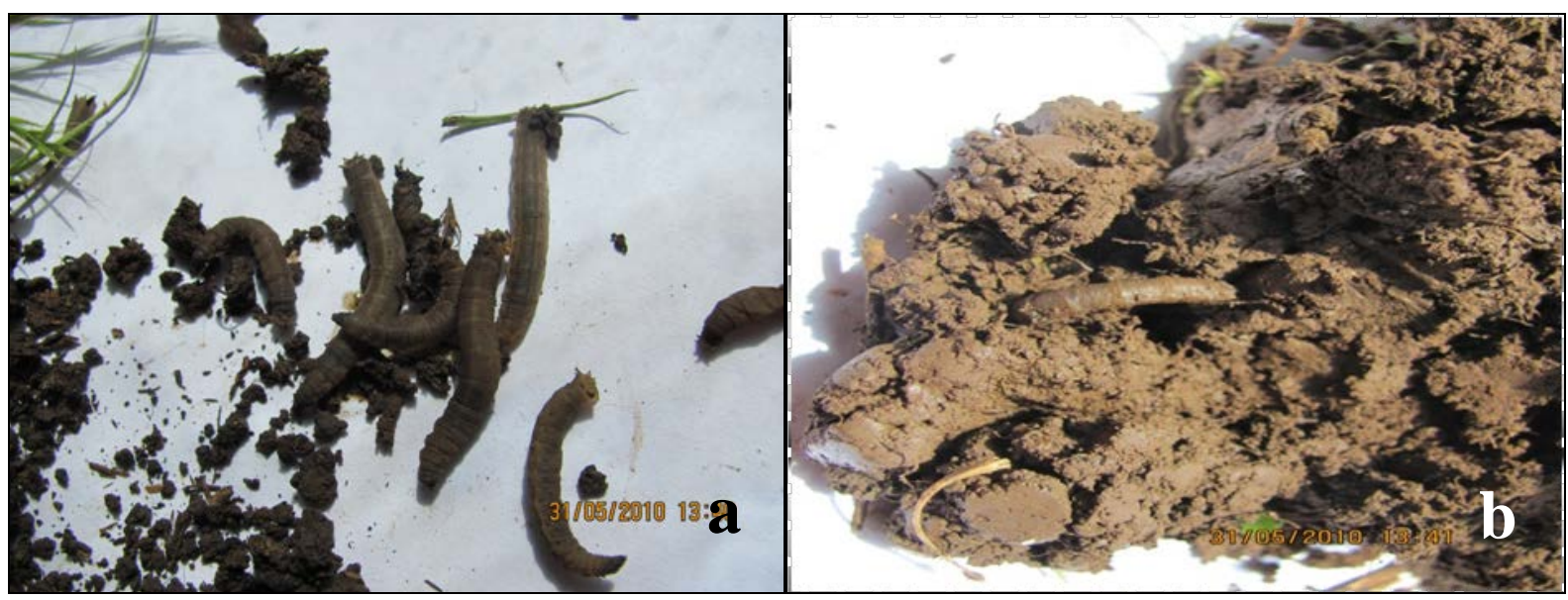

Şekil 2. Tipula orientalis larvaları (a) ve yenik zararı (b). 


\section{Tipula orientalis'in zarar durumu ve bulaşıklık oranı}

Çalışmanın yürütüldüğü Üzümlük ve Demirli köylerindeki çeltik alanlarında 2010 ve 2011 yıllarında Haziran ayından başlayarak bitkilerin \% 15-20 arasında larva tarafından zarara uğradığı tespit edilmiştir. Bu konu ile ilgili olarak yapılan literatür araştırmasına göre İngiltere'de yapılan bir çalışmada, bu larvaların mera alanlarındaki toprak içinde çok sayıda bulunduğu ve buralarda çoğaldığı bildirilmiştir (Brindle, 1959). Gelhaus (2005) tarafından İngiltere'de yapılan bir çalışmada, T. palludosa'nın yeni dikilen fidanlık alanları da içine alan mera ve çimle kaplı alanların zararlısı olduğu ve daha önce buralarda görülmediği vurgulanmaktadır. Bu türün yumurta, larva ve pupalarının torf ile kaplı olan çimde veya fidanların toprağı içinde yayıldığı bildirilmektedir. ABD Sanfransisko'da yapılan bir çalışmada, Tipula spp.'nin bu kentin limanı civarındaki alanlarda bulunduğu ve 2011 yıına kadar bu zararlının zarar yaptığına dair herhangi bir kayıt olmadığı belirtilmiştir. Ayrıca zararlının çok fazla bir yoğunluk oluşturmamasına karşın en çok nisanağustos ayları arasında tuzaklarda yakalandığı vurgulanmıştır (Byers \& Arnaud, 2011). Alexander (2009) tarafından 2009 yılında Himalaya'da yapılan bir çalışmada Tipula spp.'nin yeni ve çok az bilinen bir zararlı olduğu, Kumao ve Skim ile Assam bölgelerine kadar olan bir alanda örnekleme yaptıktan sonra Pediciine bostan sineğinin üç türünün tanımını vermiştir.

Qian (1982) Çin'in Yunnan Bölgesi'nde Tipula aino Alexander'ın biyolojisi ile ilgili olarak yapmış olduğu çalışmada, zararıının larvasının çeltik, buğday ve çimlik alanların kök bölgesine saldırdığı ve yılda 5 yada 6 döl verdiği ve larva veya ergin olarak toprakta kışladığı belirtmiştir. Yu et al. (1993) Çin'in Heilongjiang Bölgesi'nde yapmış oldukları çalışmada Tipula sp.'nin öncelikli habitat alanlarının soğuk bataklık ve çayırlık alanlar olduğunu ve bunların tohuma saldırdığını belirtmektedirler. Yine aynı araştırıcılar tarafından larvanın mayıs ayının sonunda en fazla beslenme kapasitesine ulaştığı ve bunlarla mücadelede tohum ekiminden önce $\% 2,5$ methylparathion [parathion-methyl] ve $\% 3$ carbofuran uygulanmasının zararlıyı kontrol altına aldığı vurgulanmaktadır.

Dong Sang \& Jong Eun (2007) tarafından Kore'de yapılan çalışmada, Tipula latemarginata Alexander, T. nova Walker ve $T$. aino Alexander türlerinin biyolojisi çalışılmıştır. Türlerin biyolojileri araştırmalarındaki sürvey çalışmaları Neaseong sulak alanlarının üç merkezinde 2001 ve 2005 yılları arasında gerçekleştirilmiş, biyoloji çalışmaları ise laboratuvarda yürütülmüştür. Türlerin larval habitatlarının belirlenmesi için akarsu, nehir, çeltik alanları, nemli yerler ile sızıntılı akıntıların olduğu alanlar seçilmiştir. Tipula larvalarının herbivor olduğu yeni çıkmış birinci dönem larvaların yumuşak algler üzerinde beslendiği ve larvanın kademeli olarak yaprak, gövde ve kök bölgesinde beslendiği belirtilmiştir.

Karacadağ etrafında yetiştiriciliği yapılan çeltiklerde zararının larvaları, yeni filizlenmiş bitkinin kök kısmının hemen üst tarafından kesilmesi sonucu zarar oluşturmakta daha sonra bitki gelişemeyip kırııp düşmekte ve o alanda sanki hiç ekim yapılmamış gibi bir görünüm oluşturarak boşluklar meydana getirmektedir. Bölge illerinde çeltik haziran ayının ilk haftasında ekilmekte, zararlı larvaları tohum atıldıktan yaklaşık bir hafta sonra zarar yapmaktadır. Bu dönemde zararlı ile mücadele büyük önem taşımaktadır. Mücadele edilmediği zamanlarda tarlada yeni filizlenmiş tohuma zarar verdiğinden zararın oluştuğu alanlarda bitki gelişememekte sonuçta üreticiler tarafından yeniden ekim yapma zorunluluğu oluşmaktadır. Bu yüzden Türkiye'nin diğer illerinde çeltik üreticilerinin yaptığı gibi suyu kesmeden tava oluşturarak zararlı larvaları ile kültürel olarak mücadele edilmesi büyük önem taşımaktadır. 


\section{Tipula orientalis'in ergin ve larvalarının popülasyon gelişimi}

Tipula orientalis'in Şanlıurfa İlindeki ergin popülasyon gelişimi Şekil 3'de larva popülasyonu ise Şekil 4'de verilmiştir.

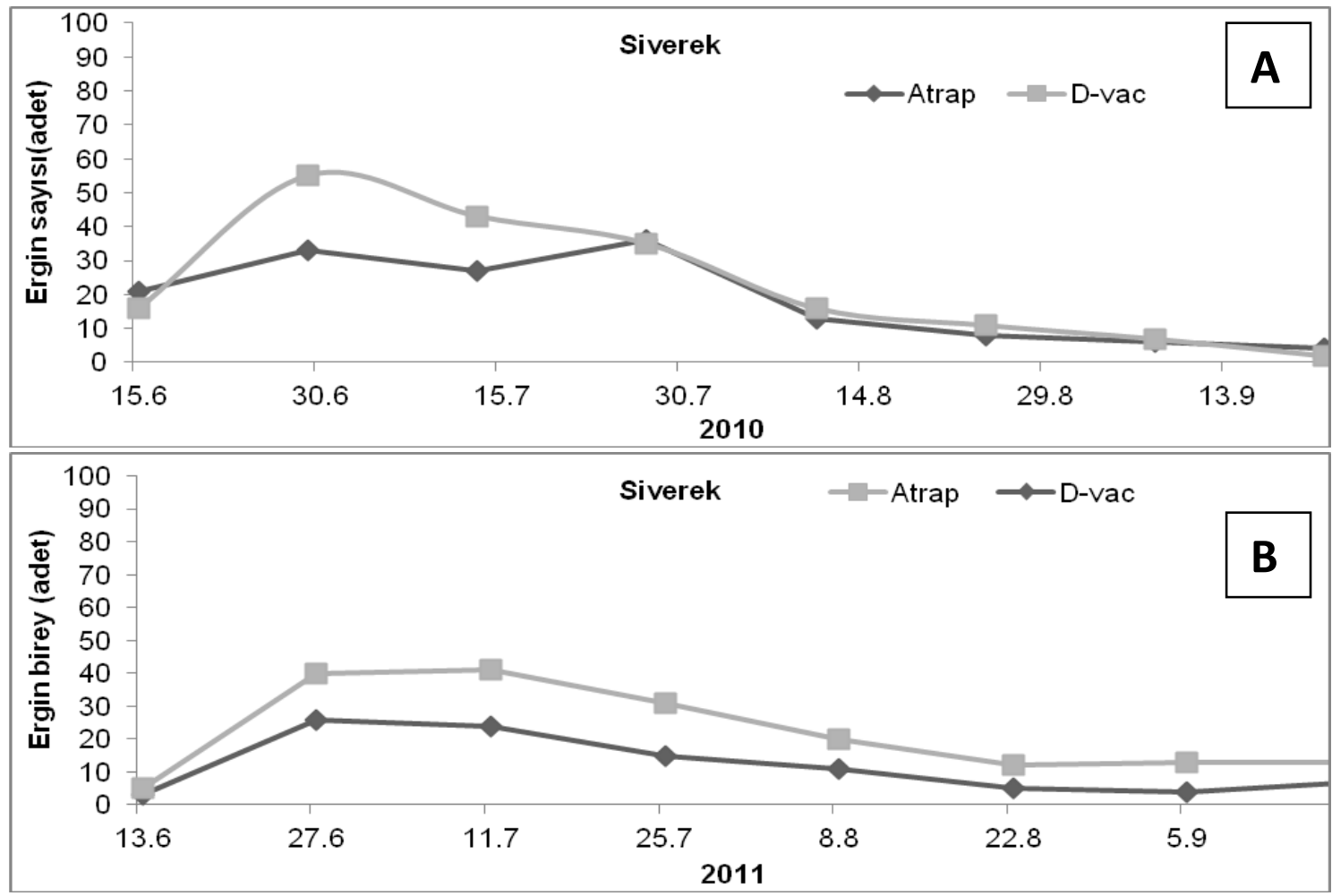

Şekil 3. Şanlıurfa Siverek Üzümlük Köyü çeltik alanlarında Tipula orientalis'in 2010 (A) ve 2011 (B) yıllarındaki ergin popülasyon seyri.

Şekil 3 incelendiğinde, Şanlıurfa Siverek Üzümlük Köyü'nde 2010 yılında 30 Haziran, 15 Temmuz ve 30 Temmuz tarihlerinde 3 tepe noktasının oluştuğu görülmesine karşın en yoğun ergin tespiti her iki yılda da 30 Haziran ve 15 Temmuz tarihlerinde görülmüştür. Oluşan 3 tepe noktası Temmuz ayı ortalarına kadar devam etmiş ancak bu tarihten itibaren popülasyonda düşme görülmüştür. Şanlıurfa Siverek Üzümlük Köyü'nde 2011 yılında 29 Haziran, 13 Temmuz ve 27 Temmuz tarihlerinde sırasıyla 55,43 ve 35 ergin birey/D-vac, atrapta ise aynı tarihlerde sırasıyla 33,27 ve 36 birey yakalanırken en yüksek popülasyon 29 Haziran tarihinde tespit edilmiş popülasyon 30 Temmuz tarihinden sonra düşüş göstermiştir.

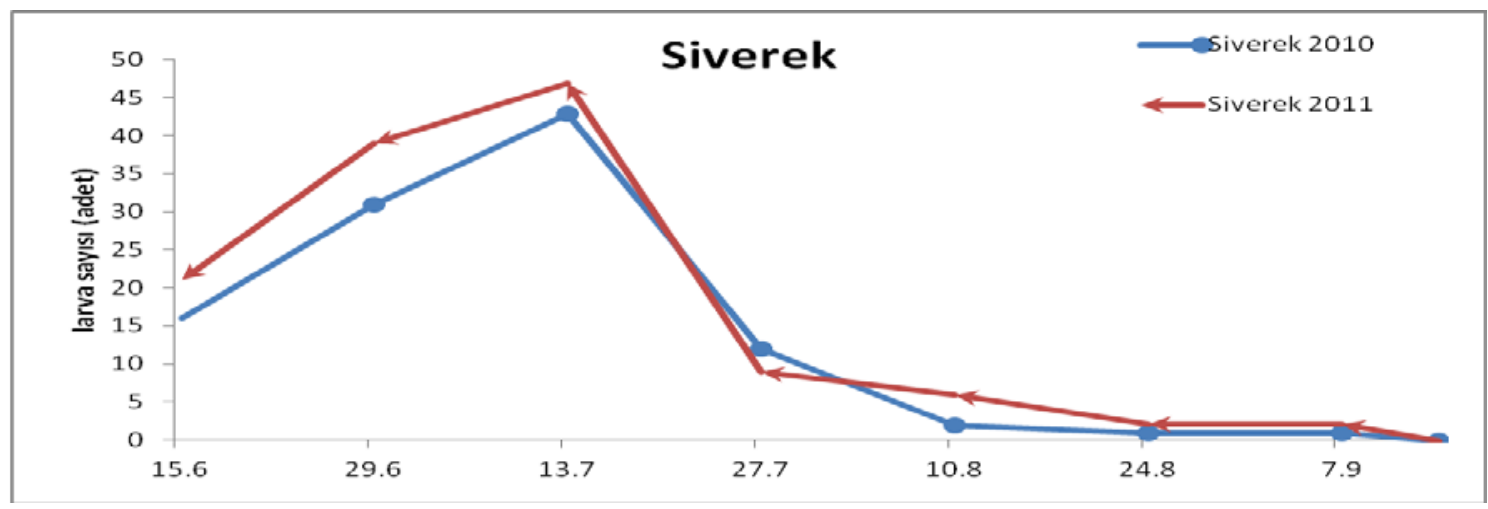

Şekil 4. Şanlıurfa Siverek Üzümlük Köyü çeltik alanlarında Tipula orientalis'in 2010 ve 2011 yıllarındaki larva popülasyon seyri. 
Şekil 4 incelendiğinde, zararlıya ait larvanın haziran ayının ikinci haftasından itibaren görülmeye başladığı Temmuz ayının ortalarında en yüksek yoğunluğa ulaştığı ve Temmuz ayının son haftasından itibaren de popülasyonlarının önemli oranda düştüğü görülmektedir. Şanlıurfa Siverek Üzümlük Köyü lokasyonunda 2010 ve 2011 yıllarında tespit edilen T. orientalis'e ait larvalar özellikle 15 Haziran-15 Temmuz arasındaki bir aylık periyotda popülasyonu artmakta ve çeltik bitkisine zarar vermektedir.

Diyarbakır ili'ne bağı olan Ergani, Çınar ve Hazro ilçelerinde karacadağ çeltiği yetiştirilmektedir. Bu alanlarda $T$. orientalis'in ergin ve larvaları sezon boyunca atrap ve D-vac yardımıyla takip edilmiş, elde edilen sonuçlar Şekil 5, 6, 7 ve 8'de verilmiştir. Zararlının larvaları her 3 ilçede de Haziran ayının başlarından Temmuz ayının ikinci haftasına kadar yoğunluk göstermekte ve zarar oluşturmaktadır.

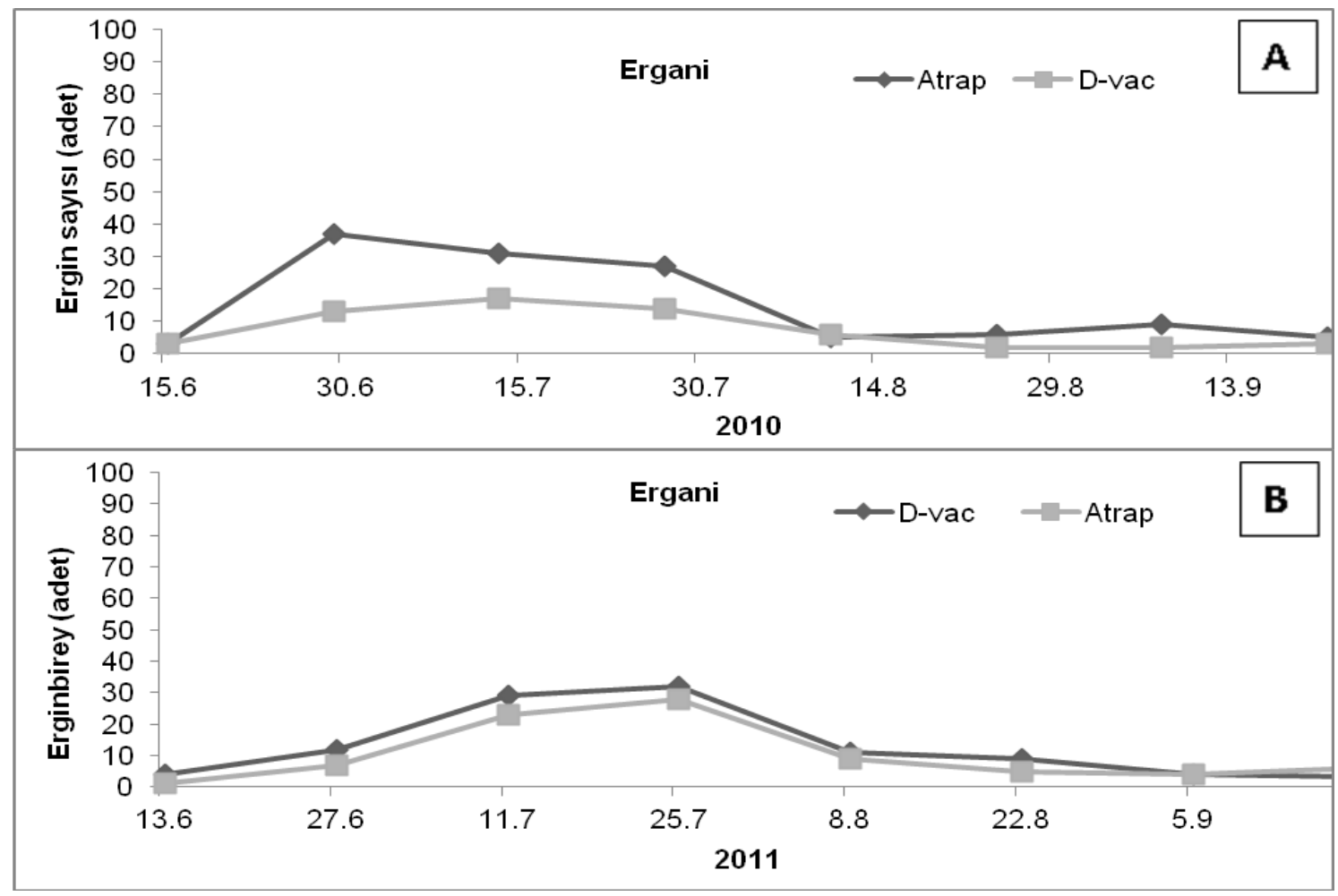

Şekil 5. Diyarbakır Ergani Demirli Köyü çeltik alanlarında Tipula orientalis'in 2010 (A) ve 2011(B) yıllarındaki ergin popülasyon seyri.

Şekil 5 incelendiğinde, T. orientalis erginleri 2010 yılında 30 Haziran, 15 ve 30 Temmuz tarihlerinde 3 tepe noktası oluşturmuştur. Bu tepe noktalarında atrapta sırasıyla 37,31 ve 27 birey yakalanırken D-vac ile aynı tarihlerde 13, 17 ve 14 birey elde edilmiştir. Aynı deneme alanında 2011 yılında ise Ergani Demirli Köyü'nde 11 ve 25 Temmuz tarihlerinde 2 tepe noktasının oluştuğu görülmüştür. Bu tepe noktalarında atrapta 11 ve 25 Temmuz tarihlerinde 23 ve 28 birey yakalanırken D-vac ile aynı tarihlerde 29 ve 32 birey yakalanmıştır. 


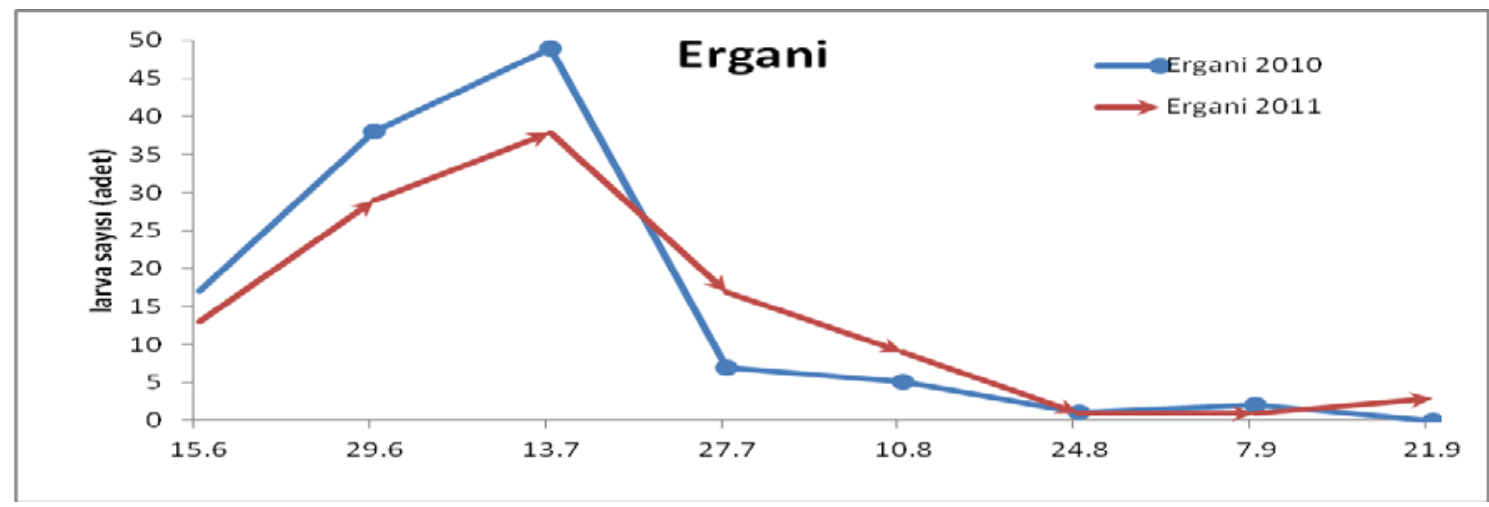

Şekil 6. Diyarbakır Ergani Demirli Köyü çeltik alanında Tipula orientalis'in 2010-2011 yıllarındaki larva popülasyon seyri.

Şekil 6 incelendiğinde Diyarbakır Ergani Demirli Köyü’nde zararlıya ait larvanın haziran ayının ikinci haftasından itibaren görülmeye başladığı Temmuz ayının ortalarında en yüksek yoğunluğa ulaştığı 2010 yılında 29 Haziran ve 13 Temmuz tarihlerinde sırasıyla 31 ve 43 larva tespit edilirken 2011 yılında ise 39 ve 47 larva yoğunluğunun tespit edildiği görülmektedir.

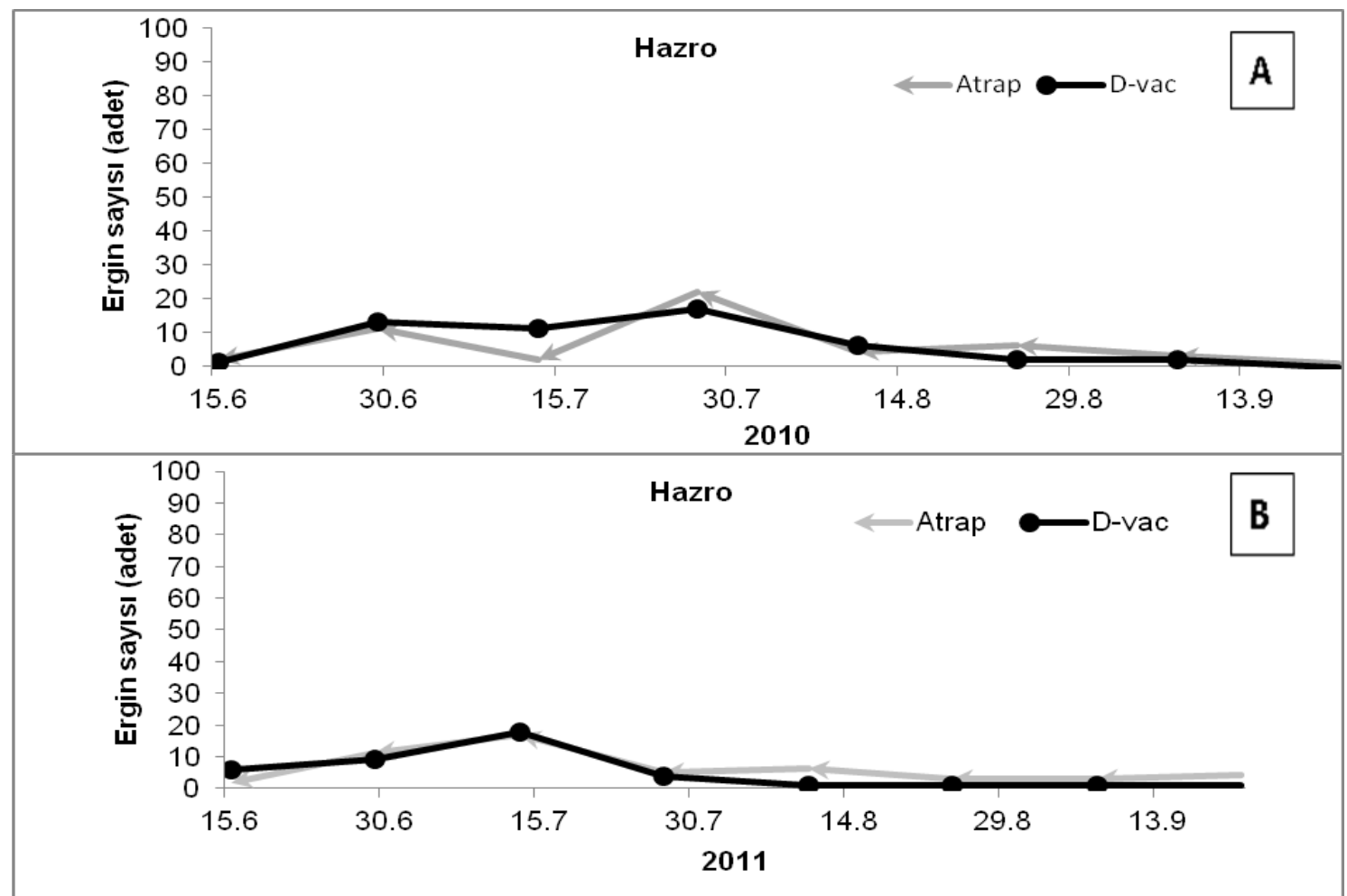

Şekil 7. Diyarbakır Hazro Düzevler köyü çeltik alanlarında Tipula orientalis'in 2010 (A) ve 2011(B) yıllarındaki ergin popülasyon seyri.

Şekil 7 incelendiğinde, zararlının ergin popülasyonu 2010 yılında Hazro İlçesi Düzevler köyündeki alanda 30 Temmuz tarihinde bir tepe noktası oluşturmuştur. Bu alanda 30 Temmuzda atrapta 22 birey, Dvac ile aynı tarihte 17 birey yakalanmış, 2011 yılında Hazro Düzevler lokasyonunda 15 Temmuz'da atrapta 17 birey, D-vac ile 18 birey yakalanmıştır. 


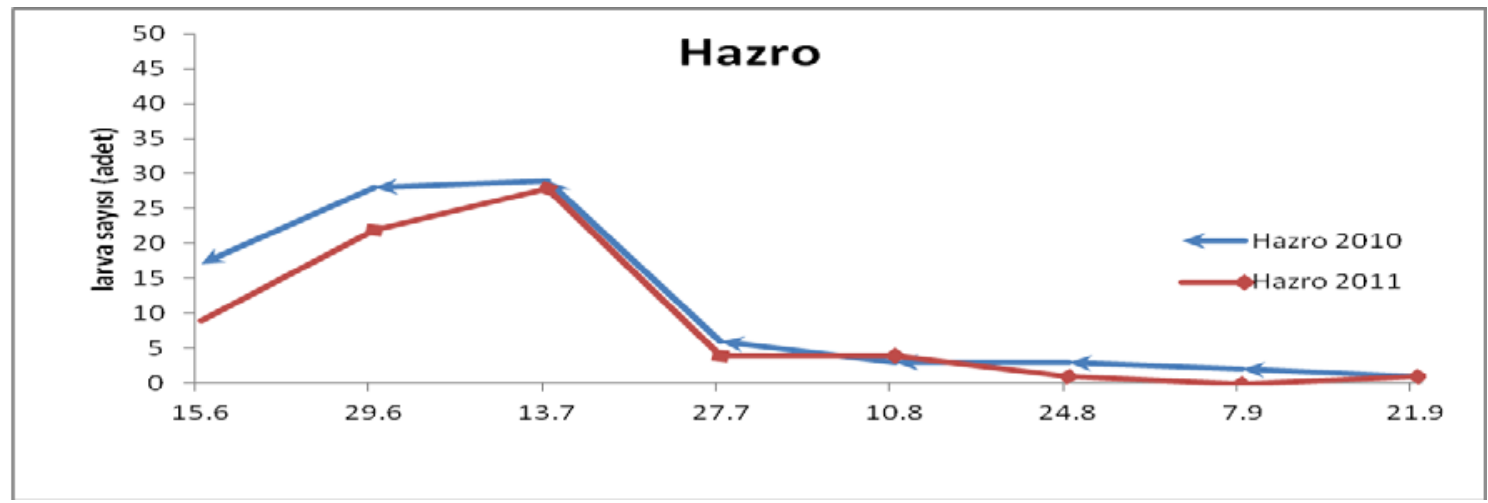

Şekil 8. Diyarbakır Hazro Düzevler köyü çeltik alanlarında Tipula orientalis'in 2010 (A) ve 2011(B) yıllarındaki larva popülasyon seyri.

Şekil 8 incelendiğinde Hazro İlçesi'ndeki deneme alanlarında larva sayısının Temmuz ayının ortalarına kadar yüksek seyrettiği ancak bu tarihten itibaren zararlıya ait larva sayısında düşme olduğu görülmektedir. 2010 yılında 29 Haziran ve 13 Temmuz tarihlerinde sırasıyla 28 ve 29 larva tespit edilirken 2011 yılında 22 ve 28 birey larva yoğunluğu görülmüştür.

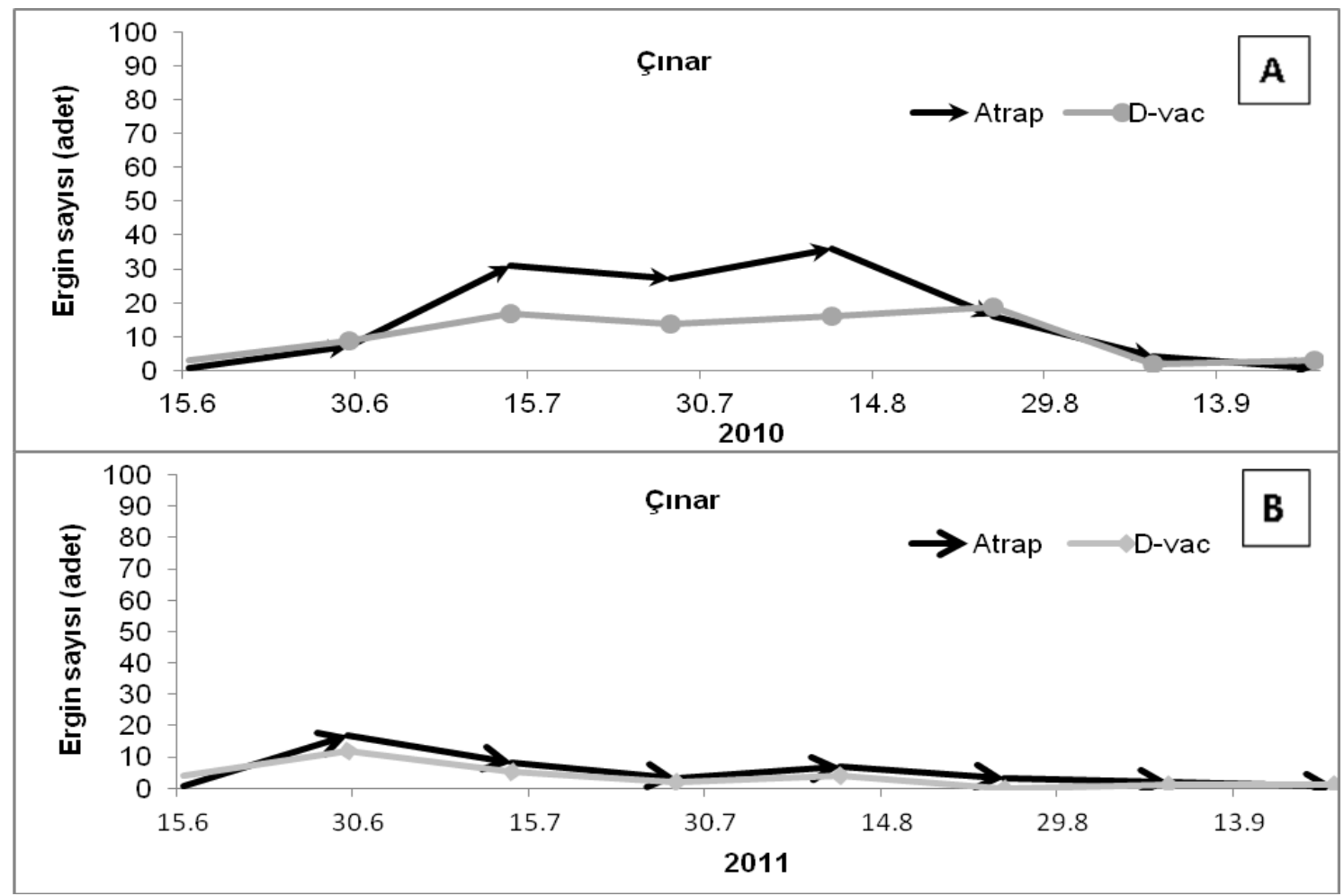

Şekil 9. Diyarbakır Çınar Kuyuluhöyük Köyü çeltik alanlarında Tipula orientalis’in 2010 (A) ve 2011 ( B) yıllarındaki ergin popülasyon seyri.

Şekil 9 incelendiğinde zararlının ergin popülasyonu 2010 yılında Çınar Kuyuluhöyük lokasyonunda 15 Temmuz ve 14 Ağustos tarihlerinde iki tepe noktası oluştururken 2011 yılında ise 30 Haziran'da bir tepe noktası oluşturmuştur. Çınar Kuyuluhöyük Köyü'nde bu tepe noktalarında atrapta 31, 27 birey yakalanırken D-vac ile aynı tarihlerde 17,14 birey yakalanmış, 2011 yılında ise Kuyuluhöyük Köyü'nde bu tepe noktasında atrapta 17 birey yakalanırken D-vac ile aynı tarihlerde 12 birey yakalanmıştır. 


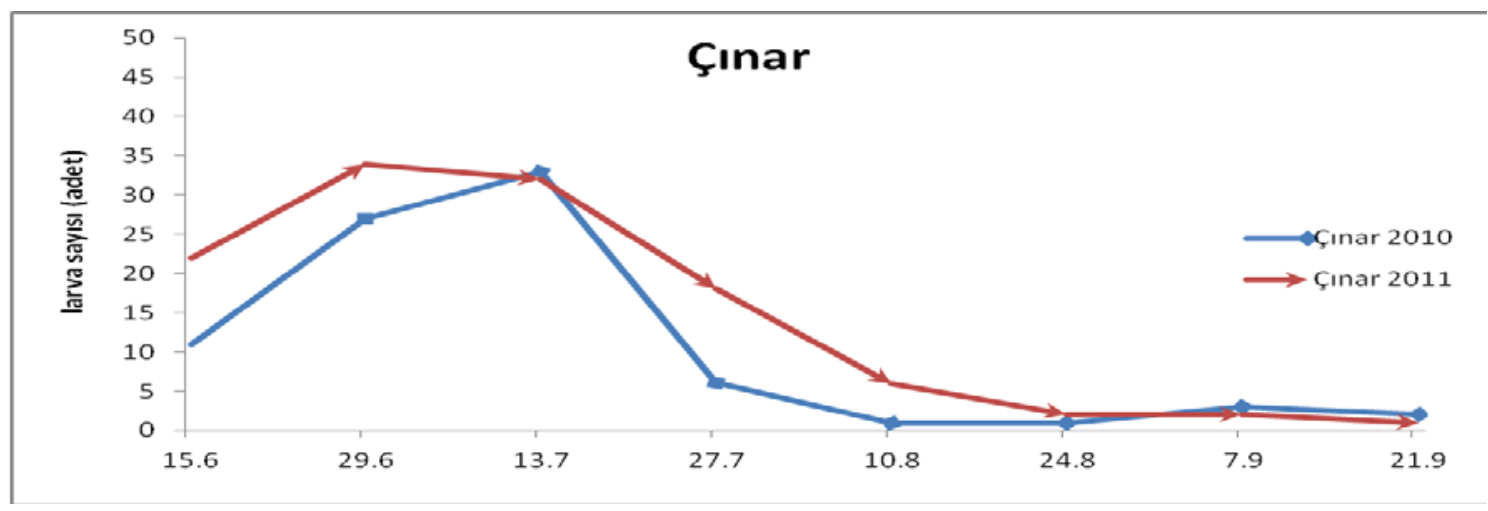

Şekil 10. Diyarbakır Çınar Kuyuluhöyük Köyü çeltik alanlarında Tipula orientalis'in 2010 (A) ve 2011(B) yıllarındaki larva popülasyon seyri.

Zararlıya ait larva Çınar Kuyuluhöyük Köyü lokasyonu deneme alanında 2010 ve 2011 yıllarında 29 Haziran ve 13 Temmuz tarihlerinde iki tepe noktası oluşturmuştur. Bu alanda toplanan birey sayısı 2010 yılında sırasıyla 27 ve 33 birey olurken 2011 yılında ise sırasıyla 34 ve 32 birey larva toplanmış olup bu tarihten sonra zararlının larva sayısında ve zararında azalma tespit edilmiştir (Şekil 10).

Tipulidae türleri konusunda gerek Türkiye'de ve gerekse de yurt dışında değişik araştırıcıların çalışmaları dikkati çekmektedir. Gelhaus tarafından 2005 yılında Kuzey Amerika'da yapılan bir çalışmada, Tipula paludosa Mg. zararlısının daha çok çimenlik ve mera alanlarında görüldüğü ve bunların tahıl ve diğer ürünlerin potansiyel zararlısı olduğu bildirilmektedir. Bu zararlının Avrupa'da çok fazla sayıda ürüne saldırdığı ve ana zararlı olarak göz önüne alındığı belirtilmektedir (Gelhaus, 2005). Ingiltere'de yapılan bir çalışmada Tipula oleracea L., T. paludosa Mg. ve T.czizeki De Jong türleri belirlenmiştir. Bu türlerin larvalarının öncelikle mera alanlarındaki toprak içinde çok sayıda bulunduğu, tarımsal ürün zararlısı olarak da sadece T. paludosa'nın olduğu bildirilmektedir (Brindle, 1959). Amerika'da Batı Merkez Kaliforniya'da yapılan bir çalışmada, Tipula oleracea'nın daha çok Avrupa'dan gelen ticari amaçı gemilerle Amerika'ya ulaştığı, bu gemilerde dengeyi sağlamak için toprak kullanıldığı ve bu toprakta yumurta, larva ve pupalarının bulunduğu ve bu şekilde taşınarak Amerika'nın sahil şeridine ulaştığı belirtilmektedir (Byers \& Arnaud, 2011). Bu zararlı 2003-2009 yılları arasında modifiye edilmiş Malaize tuzağı ve ışık tuzağı ile yakalanmış ve yılın her ayında yakalanmasına rağmen nisan-ağustos ayları arasında toplandığı belirtilmiştir (Byers \& Arnaud, 2011). Koç et al. (2012) yılında yapmış oldukları faunistik bir çalışmada, Tipula erginlerinin kısa ömürlü türler olduğu ve bunların nektarla beslendiği, orman, çalılıkların gölge alanları ile nemli topraklarda bulunduğu bildirilmektedir (Koç et al., 2012).

Tipula orientalis Lackschewitz türü çok geniş yayılışlı kozmopolit bir tür olup yakınında akarsu, dere olan buğday ve çeltik tarlalarında bulunur. Tipulidae larvalarının zarar verdiği önemli bir ürün çeltiktir. Zarar potansiyeli çok yüksek olmayan bu zararlı bölgemiz çeltik alanlarında zaman zaman zararlara neden olmaktadır. Bilindiği üzere Türkiye'de çeltik yetiştiriciliği sulama tavaları oluşturularak yapılmakta ancak Güneydoğu Anadolu Bölgesi'nde ise salma sulama şeklinde ve üç günde bir tarlaların sulanması şeklinde yapılmaktadır. Yapılan bu sulama şekli $T$. orientalis gibi zararılırın larvalarının gelişmesi ve zarar oluşturması için uygun bir ortam oluşturmaktadır. Bu zararlı bu alanlarda ana zararlı konumunda olmayıp hayatını sürdürmektedir.

\section{Teşekkür}

Çalışmalar boyunca hem laboratuvar hem de arazi çalışmalarında kolaylaştırıcı yaklaşımı ve katkılarından dolayı Doç. Dr. İnanç ÖZGEN'e (Fırat Üniversitesi, Baskil Melek Yüksek Okulu Bahçe Tarımı Bölümü), zararının larva ve erginlerinin tür teşhislerini yapan değerli hocamız Doç. Dr. Hasan KOÇ'a (Muğla Üniversitesi, Fen Fakültesi, Biyoloji Bölümü) teşekkür ederiz. 


\section{Yararlanılan Kaynaklar}

Alexander C.P., 2009. New or little-known species of exotic Tipulidae (Diptera). XV. Systematic Entomology. DOI:10.1111/j.1365-3113.1968.tb00196.x

Anonymous, 2009. Tropikal çeltik alanlarında bulunan çeltik zararılıarını önleyici ekolojik mühendislik çalışmaları için örnekleme metodları-(Erişim tarihi: Haziran 2013). (Web sayfası: http://ricehoppers.net/wpcontent/uploads/2011/02/EE-protocol-_Revised-Feb2011_2.pdf).

Anonymous, 2010. Gıda, Tarım ve Hayvancılık İI Müdürlüğü, Proje İstatistik Şube Müdürlüğü verileri- (Web sayfası: http://diyarbakir.tarim.gov.tr/) (Erişim tarihi: Haziran 2013).

Anonymous, 2013. Tahıllar içinde buğdaydan sonra gelen en önemli ürün: Çeltik (Web sayfası: http://muratpalabiyik.blogcu.com/tahillar-icinde-bugdaydan-sonra-gelen-en-onemli-urun-celtik/8032889) (Erişim tarihi: Temmuz 2013).

Brindle, A., 1959. Notes on the larvae of the British Tipulinae (Dipt.:Tipulidae) Part 6- The larvae of the Tipula oleracea L. group.. Ent. Mon. Mag., 95 (Web sayfası: http://eurekamag.com/research/023/185/023185757.php) (Erişim tarihi: Haziran 2013).

Byers, W. G. \& H. P. Arnaud, 2011. Tipula oleracea Linnaeus in West-Central California (Diptera: Tipulidae). Journal of the Kansas Entomological Society, 84(2):153-154.

DongSang, K. \& L. JongEun, 2007. Biology of three species of the genus Tipula (Diptera: Tipulidae) in Korea. Korean Journal of Applied Entomology, 46 (2): 201-212.

Gelhaus, J., 2005. The Crane-Fly Tipula (Tipula) oleracea (Diptera:Tipulidae) reported from Michigan; a new pest of Turfgrass in Eastern North America. The Great Lakes Entomologist, 38(1-2): 97-99.

Koç,H., O. Özgül, A. Tonguç \& M. Barlas, 2012. The Tipulidae fauna of Southwestern Turkey. Zoology in the Middle East, 57:115-118.

Qian, K. C., 1982. A preliminary study on the biology of Tipula aino Alexander. Insect Knowledge, 19(5): 9-11.

Mutlu, Ç., E. Sertkaya \& Ş. Güçlü, 2008. Diyarbakır İli ikinci ürün mısır alanlarında bulunan Cicadellidae (Homoptera) türleri ve yayılış alanları. Türkiye Entomoloji Dergisi, 32(4): 281-301.

Yılmaz, E. \& Y. Karsavuran, 2009. "İzmir ili Mısır alanlarında Zygnidia pullula (Boheman, 1845) ve Asymmetresca decedens (Paoli) (Hom.; Cicadellidae)'in popülasyon değişimi, 25”. Türkiye III Bitki Koruma Kongresi Bildirileri, 15-18 Temmuz Van, 345s.

Yu, X. Q., J. H. Wang, T. F. Wan, S. H. Ni, F. J. Xu, \& Y. J. Wan, 1993. Study on the bionomics of Tipula sp. and its control. Entomological Knowledge, 30 (1): 4-6. 